\title{
Denosumab, a RANK ligand inhibitor, for the management of bone loss in cancer patients
}

This article was published in the following Dove Press journal:

Clinical Interventions in Aging

3I August 2012

Number of times this article has been viewed

\author{
Andrew J Yee \\ Noopur S Raje \\ Division of Hematology-Oncology, \\ Massachusetts General Hospital \\ Cancer Center, Boston, MA, USA
}

\begin{abstract}
Bone loss is a common side effect of cancer treatments, especially antihormonal treatments used in the treatment of breast and prostate cancer. Denosumab is a monoclonal antibody given subcutaneously that inhibits osteoclast activity by targeting the RANK ligand. It is effective in settings ranging from preventing skeletal-related complications in cancer patients with metastatic disease to increasing bone mineral density in patients with osteoporosis. In cancer patients with early stage disease, denosumab can attenuate bone loss from antihormonal treatments, and in prostate cancer, may reduce disease progression. Here, we will discuss the important role denosumab may play in the management of bone loss in patients with cancer.

Keywords: denosumab, zoledronic acid, bone loss, breast cancer, prostate cancer
\end{abstract}

\section{Introduction}

Bone loss and its associated risk of fracture is an important issue for the aging patient population. This concern is magnified in patients with cancer. ${ }^{1}$ In the United States, the most commonly diagnosed cancers for women and men are breast and prostate cancer, respectively. ${ }^{2}$ Treatments for these malignancies, especially antihormonal therapies and supportive treatment with glucocorticoids, are associated with increased bone resorption. ${ }^{3}$ Furthermore, these treatment-related side effects can synergize with other risk factors for fracture, such as age, prior fracture history, and family history of fracture as well as lifestyle factors such as smoking, low calcium intake, and vitamin D deficiency, further increasing the risk of fracture. ${ }^{4}$

Strategies aimed at improving bone health in cancer patients include lifestyle modifications and calcium and vitamin D supplementation. Moderate levels of activity such as walking and quitting smoking have been associated with a decreased risk of hip fracture. ${ }^{5-7}$ Current expert consensus guidelines recommend $1200 \mathrm{mg}$ of elemental calcium supplementation with 800 to 1000 IU of vitamin D daily. ${ }^{3,8}$ The usage of pharmacologic therapies with bisphosphonates and now denosumab have become integral components of improving bone health in this population.

\section{Bisphosphonates}

Bisphosphonates are drugs that share a phosphorus-carbon-phosphorus backbone and decrease risk of fracture by minimizing bone resorption. They accumulate in the mineral phase of bone and reduce osteoclast activity by inhibiting farnesyl pyrophosphate synthase. ${ }^{9}$ Several Phase III clinical trials, where reduction in the rate of fracture and increase in bone mineral density were the primary endpoint, have established the role
Correspondence: Andrew J Yee Division of Hematology-Oncology, Massachusetts General Hospital Cancer Center, 55 Fruit St, Boston,

MA 02114 , USA

Tel +I 6177244000

Email ayeel@partners.org 
of bisphosphonates in the treatment of osteoporosis with daily oral alendronate (FIT), ${ }^{10}$ daily oral risedronate (VERT), ${ }^{11}$ and intravenous bisphosphonate zoledronic acid given yearly (HORIZON). ${ }^{12}$ In addition to its role in treating osteoporosis, zoledronic acid has played a core role in the management of metastatic bone disease. ${ }^{3,13-15}$

\section{Denosumab}

Denosumab has emerged as a novel and clinically effective therapeutic agent for targeting the osteoclast. Denosumab is a fully human monoclonal antibody given subcutaneously that neutralizes the receptor activator of nuclear factor $\kappa \mathrm{B}$ ligand (RANKL). RANKL is a cytokine produced by osteoblasts, which activates the RANK receptor present on osteoclast precursors and osteoclasts (see Figure 1). This signaling pathway is important for the formation, function, and survival of osteoclasts. ${ }^{16}$ Unlike bisphosphonates, denosumab does not accumulate in bone. It has a circulatory half-life of approximately 26 days, and like other monoclonal antibodies, the clearance of denosumab is through the reticuloendothelial system and does not depend on renal clearance. ${ }^{17}$

Similar to the indications for bisphosphonates like zoledronic acid, denosumab is indicated for the prevention of skeletal-related events in cancer patients with bone metastases and in the treatment of osteoporosis. Initial studies including a Phase II trial showed that denosumab was able to suppress bone turnover and decrease skeletal-related events in patients who were already receiving intravenous bisphosphonates (pamidronate and zoledronic acid). ${ }^{18}$ Subsequently, three Phase III clinical trials confirmed the effectiveness of denosumab compared to zoledronic acid in patients with bone metastases for preventing skeletal-related events. The FDA approved the use of denosumab in this population in 2010 . The patient populations examined included breast cancer, ${ }^{19}$ prostate cancer, ${ }^{20}$ and cancers other than breast and prostate (mainly lung and multiple myeloma). ${ }^{21}$ In these studies, patients were randomized to denosumab $120 \mathrm{mg}$ subcutaneously versus zoledronic acid $4 \mathrm{mg}$ intravenously (or equivalent creatinine clearance-adjusted dose) every 4 weeks. In the first two studies, denosumab was superior to zoledronic acid in delaying skeletal-related events: median time to this event was not reached in the denosumab group versus 26.4 months $(P=0.01)$ in the zoledronic acid group for breast cancer patients, ${ }^{19}$ and 20.7 months in the denosumab group versus 17.1 months $(P=0.008)$ in the zoledronic acid group in the study of prostate cancer patients. ${ }^{20}$ There was a greater suppression of bone turnover markers in the patients treated with denosumab compared to zoledronic acid. There was no difference in overall survival between patients treated with denosumab versus zoledronic acid. Finally, in a third study including all other cancer types (excluding breast and prostate cancer patients) and a subset of patients with multiple myeloma, denosumab was not inferior to zoledronic acid. ${ }^{21}$ An ad hoc analysis showed that survival was worse in the multiple myeloma cohort, which comprised $10 \%$ of the study population. However, this interpretation is limited given the small number of patients with multiple myeloma in this study. Given this finding, denosumab is not indicated at this time for the prevention of skeletal-related events in patients with multiple myeloma. There is currently a Phase III study in

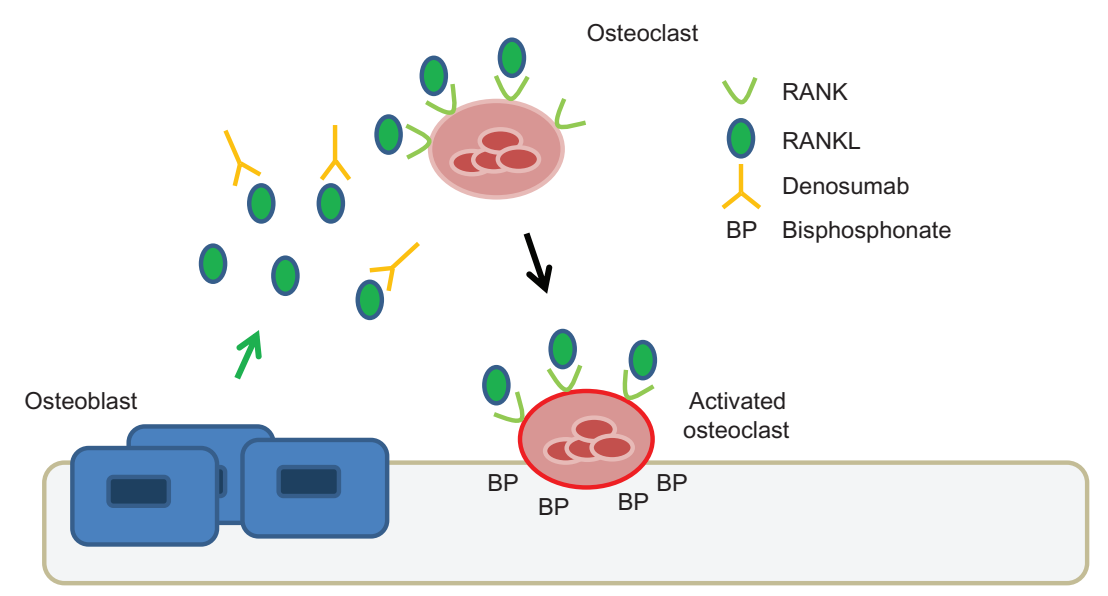

Figure I Mechanism of action of denosumab compared to zoledronic acid.

Notes: RANKL is secreted by bone marrow stromal cells and osteoblasts. RANKL binds to the RANK receptor on osteoclasts and promotes osteoclast differentiation and activity. Denosumab is a fully human monoclonal antibody that binds to RANKL and thereby inhibits the activation of osteoclasts by RANKL. Bisphosphonates (for example, zoledronic acid) bind to bone, enter, and inhibit bone resorption by osteoclasts.

See review by Baron et al ${ }^{17}$ for details.

Abbreviations: RANK, receptor activator of nuclear factor $\kappa B$; RANKL, RANK ligand. 
progress that focuses on patients with multiple myeloma and compares the effectiveness of denosumab to zoledronic acid in preventing skeletal-related events (NCT01345019).

This review will focus on the use of denosumab to minimize bone loss specifically in the cancer patient population and expand on a recent review of the clinical utility of denosumab for the treatment of bone loss. ${ }^{22}$ Table 1 summarizes some of the clinical trials of denosumab to treat bone loss in cancer patients.

\section{Denosumab in breast cancer}

Bone loss is a common complication in women undergoing treatment for breast cancer. The causes for bone loss include chemotherapy-induced ovarian failure and anti-hormonal therapy with aromatase inhibitors.

Among premenopausal women undergoing adjuvant chemotherapy for early stage breast cancer, around two-thirds of women will experience early menopause. ${ }^{23-25}$ In one study of early stage breast cancer patients undergoing adjuvant chemotherapy, among the patients who experienced ovarian failure ( 35 out of 49 patients), there was rapid bone loss. ${ }^{25} \mathrm{At}$ 6 months, there was a $4 \%$ decrease in total spine bone mineral density (BMD), whereas there was no significant change in the women who did not have ovarian failure.

For postmenopausal women with early stage estrogen receptor positive breast cancer, aromatase inhibitors (AIs) are the cornerstone of adjuvant therapy. ${ }^{26}$ AIs inhibit the production of estrogen from androgens by aromatase in peripheral tissues (principally subcutaneous adipose tissue in postmenopausal women) and thereby decrease circulating estrogen levels. ${ }^{27}$ A major limitation with AIs is their side effect of increased bone resorption and fractures. A meta-analysis of seven trials and over 30,000 women on AIs and tamoxifen as primary adjuvant therapy found that there was a $47 \%$ increase in the odds of bone fracture in the AI cohort compared to tamoxifen $(P<0.001)$; the difference in the fracture rate was $7.5 \%$ versus $5.2 \%$ in the $\mathrm{AI}$ and tamoxifen groups, respectively. ${ }^{28}$

The effect of denosumab on minimizing bone loss in these women was investigated in the Hormone Ablation Bone Loss Trial in Breast Cancer (HALT-BC), a Phase III study of women with early stage, nonmetastatic, estrogen receptor positive breast cancer who also had evidence of low bone mass. ${ }^{29}$ All patients were required to have a BMD of lumbar spine, total hip, and femoral neck corresponding to a T-score of -1 to -2.5 . A total of 252 women were randomized to denosumab and given $60 \mathrm{mg}$ subcutaneously every 6 months versus placebo for a total of four doses while on aromatase inhibitor therapy; the specific aromatase inhibitor was not specified in the trial. This dose of denosumab is the same dose used for management of osteoporosis and is significantly less than the dose used for treatment of metastatic bone disease (120 mg subcutaneously every 4 weeks). The primary endpoint of this study was a percentage change from the baseline in lumbar spine bone mineral density at 12 months. At 1 year, the lumbar spine BMD increased by $4.8 \%$ in the denosumab arm while it decreased by $0.7 \%$ in the placebo group $(P<0.0001)$. At 2 years, $80 \%$ of the denosumab group had an increase greater than $3 \%$ in the lumbar spine BMD compared to $13 \%$ in the placebo arm. There were no vertebral fractures reported in the study. Denosumab was tolerated well without any unique side effects compared to the placebo arm. Osteonecrosis of the jaw did not occur in this study. A larger study is ongoing of denosumab versus placebo in early stage breast cancer patients where the primary endpoint is the time to first clinical fracture (NCT00556374). In September 2011, the use of denosumab to increase bone mass in women receiving aromatase inhibitor therapy in breast cancer was approved by the FDA.

Results of the HALT-BC trial are comparable to trials with similar patient populations and design with bisphosphonate zoledronic acid. In the Z-FAST (North American) ${ }^{30}$ and ZO-FAST (European) ${ }^{31}$ studies, postmenopausal women with early stage breast cancer on letrozole were randomly assigned to immediate zoledronic acid versus delayed zoledronic acid. Immediate zoledronic acid was given $4 \mathrm{mg}$ intravenously every 6 months for 5 years; delayed zoledronic acid was given only if the T-score fell below -2 or if a fracture was seen. At 36 months, in the ZO-FAST trial, the mean change in LS BMD was $4.39 \%$ in the immediate zoledronic acid group versus $-4.9 \%$ in the delayed zoledronic acid group $(P<0.0001)$. Of note, zoledronic acid has not been compared directly with denosumab in this population.

In addition to its effects on attenuating bone loss, reports of the favorable effect of zoledronic acid on breast cancer recurrence have received a significant amount of attention. In the Austrian Breast and Colorectal Cancer Study Group-12 Trial (ABCSG-12), 1803 premenopausal women with hormone receptor positive, Stage I or II breast cancer were randomized to goserelin plus either tamoxifen or anastrozole, with or without zoledronic acid. ${ }^{32}$ Zoledronic acid was given $4 \mathrm{mg}$ intravenously every 6 months, though for the initial 254 patients, zoledronic acid was given $8 \mathrm{mg}$ every 4 weeks. At a median follow-up of nearly 4 years, diseasefree survival was $94 \%$ in the group that received zoledronic acid compared to $90.8 \%$ in the group without zoledronic acid, ie, a $3.2 \%$ absolute reduction in the risk of disease 
progression $(P=0.01)$. When the results of this study were recently updated with a median of 62 months of follow-up, the difference in disease-free survival was maintained, with $92 \%$ in the zoledronic acid arm versus $88 \%$ in endocrine therapy alone $(P=0.008) .{ }^{33}$

In contrast, the Adjuvant Zoledronic Acid to Reduce Recurrence (AZURE) study found that adjuvant zoledronic acid did not affect disease-free recurrence. ${ }^{34}$ This was a larger study of 3360 women receiving standard adjuvant systemic therapy randomized to either zoledronic acid or no treatment. Overall, the findings in these studies are provocative, and suggest that agents that target the osteoclast and the bone microenvironment may favorably affect disease progression.

Currently, there is an ongoing Phase III study exploring the effect of denosumab versus placebo on disease-specific outcomes in women with early stage breast cancer at high risk of recurrence (D-CARE, NCT01077154). The primary objective of the D-CARE study is to investigate if denosumab will prolong bone metastasis-free survival in patients with Stage II or Stage III breast cancer. Denosumab or placebo will be given $120 \mathrm{mg}$ subcutaneously every 4 weeks for the first 6 months and then every 3 months for a total duration of 5 years. The motivation for this study is based on animal models suggesting that RANKL-RANK signaling plays an important role in breast cancer tumorigenesis ${ }^{35}$ and in metastasis (in melanoma mouse models). ${ }^{36}$ These preclinical findings suggest that inhibition of RANKL via denosumab, in addition to minimizing bone loss, may play a role in mitigating the progression of disease.

\section{Denosumab in prostate cancer}

Androgen deprivation therapy (ADT) with gonadotropin-releasing hormone $(\mathrm{GnRH})$ agonists is a principal treatment for patients with metastatic prostate cancer. ${ }^{37}$ It is also increasingly used as an adjuvant therapy in patients undergoing radiation therapy for high risk or locally advanced disease. ${ }^{38}$ The resulting hypogonadal state is associated with increased bone resorption and significantly increased risk of fracture, which is a major morbidity associated with ADT. ${ }^{39}$ A study of over 50,000 men in the SEER program and Medicare showed that of men with prostate cancer surviving at least 5 years after diagnosis, $19.4 \%$ of those who received ADT sustained a fracture, compared to $12.6 \%$ not receiving ADT $(P<0.001) .{ }^{40}$ Additionally, a claims-based cohort study of men with localized prostate cancer reported that the rate of fracture was significantly higher in men receiving a GnRH agonist compared to matched controls, 7.88 per 100 person-years versus 6.51 per 100 person-years, respectively $(P<0.001){ }^{41}$
To see if the effects on bone loss with ADT could be mitigated, denosumab was studied in the Hormone Ablation Bone Loss Trial in Prostate Cancer (HALT-PC), a trial of prostate cancer patients receiving ADT who did not have metastatic disease. Denosumab was given at a dose of $60 \mathrm{mg}$ subcutaneously every 6 months and compared to placebo in 1468 men. ${ }^{42}$ This dose of denosumab is the same as in the HALT-BC trial of early stage breast cancer patients. At 24 months, the bone mineral density in the lumbar spine was significantly increased by $5.6 \%$ in the denosumab group compared to a loss of $1 \%$ in the placebo group $(P<0.001)$. There was a decreased cumulative incidence of vertebral fracture at 36 months in the placebo group, of 3.9\% compared to $1.5 \%$ in the denosumab group, representing a $62 \%$ decrease $(P=0.006)$. Rates of adverse events were similar in both groups. Of note, no cases of osteonecrosis of the jaw were reported in either group. In September 2011, the FDA approved the indication of denosumab for increasing bone mass in patients with nonmetastatic prostate cancer.

The Denosumab 147 trial investigated if denosumab, in this patient population with nonmetastatic prostate cancer, could affect disease progression. ${ }^{43}$ This Phase III placebo-controlled study examined 1432 patients with high risk for the development of bone metastases (PSA $\geq 8 \mathrm{ng} / \mathrm{mL}$ or PSA doubling time $\leq 10$ months). Denosumab was given $120 \mathrm{mg}$ subcutaneously every 4 weeks, similar to the schedule in patients with known bone metastases. An important finding was that denosumab significantly increased bone metastasis free survival (defined as first occurrence of bone metastasis, symptomatic or asymptomatic, or death from any cause) by 4.2 months compared with placebo: 29.5 months with denosumab versus 25.2 months with placebo $(P=0.028)$. Overall survival did not differ between groups. Osteonecrosis of the jaw occurred in 5\% of the denosumab group versus none in the placebo group, with increasing rates of ONJ with increasing exposure to drug, of $1 \%, 3 \%$, and $4 \%$ at end of years 1,2 , and 3 , respectively.

At the time of this writing, denosumab has not been directly compared with zoledronic acid for prevention of bone loss in patients with prostate cancer.

\section{Safety of denosumab}

Denosumab is generally very well tolerated, with a low incidence of side effects. The main areas of potential clinical concern include osteonecrosis of the jaw and infection.

\section{Osteonecrosis of the jaw}

Osteonecrosis of the jaw (ONJ) is a potentially serious side effect of therapy targeting osteoclasts, which include 
Table I Summary of trials of denosumab to prevent bone loss in cancer patients

\begin{tabular}{|c|c|c|c|c|c|}
\hline Trial name & Reference & No of patients & Population & Treatment & Comments \\
\hline HALT-BC & Ellis et $\mathrm{a}^{29}$ & 252 & $\begin{array}{l}\text { Early stage breast cancer } \\
\text { patients with low bone } \\
\text { mass receiving aromatase } \\
\text { inhibitor therapy }\end{array}$ & $\begin{array}{l}\text { Denosumab } 60 \mathrm{mg} \mathrm{sc} \\
\mathrm{q} 6 \text { months } \times 4 \text { doses versus } \\
\text { placebo }\end{array}$ & $\begin{array}{l}\text { At } 12 \text { months, BMD }+4.8 \% \text { in } \\
\text { denosumab arm versus }-0.7 \% \\
\text { in placebo arm }\end{array}$ \\
\hline $\begin{array}{l}\text { ABCSG-I8 } \\
(\text { NCT00556374) }\end{array}$ & & 3400 planned & $\begin{array}{l}\text { Early stage breast } \\
\text { cancer patients receiving } \\
\text { aromatase inhibitor } \\
\text { therapy }\end{array}$ & $\begin{array}{l}\text { Denosumab } 60 \mathrm{mg} \mathrm{sc} \\
\mathrm{q} 6 \text { months } \times 4 \text { doses versus } \\
\text { placebo }\end{array}$ & $\begin{array}{l}\text { Primary endpoint is time } \\
\text { to first clinical fracture. } \\
\text { Estimated primary completion } \\
\text { date, December } 2014\end{array}$ \\
\hline $\begin{array}{l}\text { D-CARE } \\
\text { (NCT0I077I54) }\end{array}$ & & 4500 planned & $\begin{array}{l}\text { High-risk early stage } \\
\text { breast cancer patients } \\
\text { (Stage II or Stage III) }\end{array}$ & $\begin{array}{l}\text { Denosumab } 120 \mathrm{mg} \mathrm{sc} \\
\text { monthly for } 6 \text { months followed } \\
\text { by every } 3 \text { months for the } \\
\text { next } 4.5 \text { years versus placebo }\end{array}$ & $\begin{array}{l}\text { Primary endpoint is bone } \\
\text { metastasis-free survival. } \\
\text { Estimated primary completion } \\
\text { date, October } 2016\end{array}$ \\
\hline HALT-PC & Smith et a ${ }^{42}$ & 1468 & $\begin{array}{l}\text { Nonmetastatic prostate } \\
\text { cancer patients on } \\
\text { androgen deprivation } \\
\text { therapy }\end{array}$ & $\begin{array}{l}\text { Denosumab } 60 \mathrm{mg} \mathrm{sc} \\
\text { q6 months versus placebo }\end{array}$ & $\begin{array}{l}\text { At } 24 \text { months, increase } \\
\text { in BMD at lumbar spine } \\
5.6 \% \text { versus decrease } 1 \% \text { in } \\
\text { placebo. Cumulative incidence } \\
\text { of vertebral fracture } 3.9 \% \text { in } \\
\text { placebo arm versus } 1.5 \% \text { in } \\
\text { denosumab arm }\end{array}$ \\
\hline Denosumab I47 & Smith et al ${ }^{43}$ & 1432 & $\begin{array}{l}\text { Prostate cancer } \\
\text { patients at high risk } \\
\text { for developing bone } \\
\text { metastasis }\end{array}$ & $\begin{array}{l}\text { Denosumab I } 20 \text { mg sc } \\
\text { q4 weeks versus placebo }\end{array}$ & $\begin{array}{l}\text { Bone-metastasis free survival } \\
\text { longer with denosumab than } \\
\text { placebo, } 29.5 \text { months versus } \\
25.2 \text { months, respectively. }\end{array}$ \\
\hline
\end{tabular}

Abbreviations: BMD, bone mineral density; sc, subcutaneously; q, every.

bisphosphonates given intravenously and denosumab. ONJ is a form of avascular necrosis where there is persistence of exposed, necrotic bone in the oral cavity for more than 8 weeks and where there is no history of local evidence of malignancy or radiation exposure in the affected region. ${ }^{44}$

The association between osteoclast-targeted therapy and ONJ was first reported with intravenous bisphosphonates in the early 2000s. Overall, this relationship has been best described in patients receiving frequent intravenous bisphosphonate therapy such as pamidronate or zoledronic acid for prevention or management of skeletal-related complications of cancer. ${ }^{45}$

ONJ has also been observed with denosumab therapy, primarily in the cancer patient population with bone metastases where denosumab is given every 4 weeks. An integrated analysis examined the frequency of ONJ in three blinded Phase III trials in cancer patients with bone metastases comparing denosumab $120 \mathrm{mg}$ subcutaneously versus zoledronic acid $4 \mathrm{mg}$ intravenously given every 4 weeks. ${ }^{46}$ In this analysis, the cumulative rate of ONJ was similar for both arms: $1.3 \%$ and 1.8\% in year 3 for zoledronic acid and denosumab, respectively. The median time of drug exposure before ONJ was 14 months for both treatment groups. Tooth extraction was the main risk factor associated with the development of ONJ.

In trials of patients where denosumab is given every 6 months to prevent bone loss (rather than to treat metastatic disease),
ONJ has not been reported. For example, ONJ was not seen in the FREEDOM registration trial, which enrolled postmenopausal women between the ages of 60 and 90 with osteoporosis and randomized 3902 women to the denosumab arm; denosumab was given at $60 \mathrm{mg}$ subcutaneously every 6 months for 3 years. ${ }^{47}$ Similarly, in the trials where denosumab was given to prevent bone loss in patients with cancer, ONJ was not observed in the HALT-BC breast cancer trial ${ }^{29}$ or the HALT-PC prostate cancer trial. ${ }^{42}$ However, in the Denosumab 147 study, where denosumab $120 \mathrm{mg}$ was given every 4 weeks, ONJ occurred in 5\% of the denosumab arm over the course of the study. ${ }^{43}$ The absence of ONJ observed in the HALT-BC and HALT-PC bone loss prevention trials may be related to the lower intensity of denosumab administration in this patient population, as denosumab was given $60 \mathrm{mg}$ every 6 months versus $120 \mathrm{mg}$ every 4 weeks in the metastatic cancer patient population. Nevertheless, there have been case reports of ONJ where denosumab is given to prevent bone loss. For example, there were two cases of ONJ reported in patients who received denosumab for an additional 2 years after the FREEDOM trial. ${ }^{48}$

\section{Infection}

A possible effect on the immune system by denosumab was postulated based on preclinical data where RANKL was found to be a costimulatory cytokine for T-cell activation ${ }^{49}$ 
and lymphocyte development. ${ }^{50}$ However, the clinical data with denosumab is conflicting on this issue. A meta-analysis of nine randomized controlled trials where denosumab was used to mitigate bone loss in patients with osteoporosis or early breast cancer showed an increased risk for infection with an odds ratio of 4.45 (95\% confidence interval: 1.15-17.14). ${ }^{51}$ On the other hand, in the FREEDOM study (which was analyzed in the above meta-analysis), there was no clear relationship between overall infections and exposure to denosumab. ${ }^{52}$ However, skin infections such as cellulitis, including erysipelas, while infrequent, occurred significantly more in the denosumab arm $(0.3 \%)$ compared to placebo $(0.03 \%) .{ }^{47}$ These infections were not related to the injection site. ${ }^{52}$ Also related to the skin, eczema occurred more frequently in the denosumab group (3\%) compared to the placebo group $(1.7 \%)$ in this trial.

\section{Comparison with zoledronic acid}

While the risk of ONJ appears to be similar between the bisphosphonate zoledronic acid and denosumab, some side effects associated with zoledronic acid have not been reported or are less common with denosumab.

An acute phase reaction is a classic side effect of intravenous bisphosphonates and is characterized by short-term pyrexia, chills, myalgias, and arthralgias. ${ }^{53}$ In the HORIZON trial, where zoledronic acid was given yearly for osteoporosis in postmenopausal women, $31.6 \%$ of patients had pyrexia, myalgia, influenza-like symptoms, headaches, or arthralgias 3 days or fewer after the first infusion compared to $6.2 \%$ in the placebo arm. ${ }^{12}$ The incidence of acute phase reactions with denosumab is significantly lower. For example, in the trials evaluating denosumab versus zoledronic acid in patients with metastatic bone disease, acute phase reactions were seen in $10.4 \%$ with denosumab versus $27.3 \%$ with zoledronic acid $^{19}$ and $6.9 \%$ with denosumab versus $14.5 \%$ with zoledronic acid $(P<0.001) .{ }^{21}$ In other trials evaluating use of denosumab to prevent bone loss, acute phase reactions have not been reported or were not significantly different from the placebo group. ${ }^{29,42}$

Renal dysfunction is a concern with intravenous bisphosphonates like zoledronic acid. Dose adjustment for renal function is necessary with zoledronic acid, and it is contraindicated in patients with creatinine clearance $<30 \mathrm{~mL} / \mathrm{min}$. In initial studies, renal toxicity was related to dose (especially with $8 \mathrm{mg}$, which is not in clinical use, compared to $4 \mathrm{mg}$ ), and in patients receiving $4 \mathrm{mg}$ of zoledronic acid, the risk of renal dysfunction ranged from $11 \%-12.2 \%$ compared to $7 \%-10.3 \%$ with placebo. ${ }^{54,55}$ Renal dysfunction was observed less frequently with denosumab in the Phase III trials compared to zoledronic acid in the metastatic bone disease patient population. For example, in the metastatic breast cancer population, adverse events with renal toxicity occurred more frequently in the zoledronic acid arm compared to the denosumab arm, $8.5 \%$ versus $4.9 \%(P=0.001){ }^{19} 10.9 \%$ with the zoledronic acid arm versus $8.3 \%$ in the denosumab arm. ${ }^{21}$ (When given yearly for osteoporosis, renal dysfunction has not been reported for zoledronic acid.) In contrast to zoledronic acid, renal dysfunction has not been observed at a significant frequency with denosumab, either when given every 4 weeks or every 6 months for prevention of bone loss. Given these findings, dosing of denosumab does not need to be adjusted for renal function.

\section{Conclusion}

Denosumab is an effective agent for minimizing bone loss associated with certain cancer treatments. It has the advantage of convenience with subcutaneous administration and is not associated with acute phase reactions or renal toxicity. Importantly, data are emerging that demonstrate its effect on minimizing disease progression in prostate cancer. It remains to be seen if the use of denosumab to prevent bone loss in the cancer patient population will improve overall survival and how longer-term side effects such as osteonecrosis of the jaw will evolve over time. While the role of denosumab in patients with metastatic bone cancer has been established, denosumab will play an increasing role in the supportive care and treatment of patients with early stage cancer to prevent bone loss.

\section{Disclosure}

Dr Raje performs clinical research with Amgen. Dr Yee has no conflicts of interest to report.

\section{References}

1. Vallet S, Smith MR, Raje N. Novel bone-targeted strategies in oncology. Clin Cancer Res. 2010;16(16):4084-4093.

2. Siegel R, Naishadham D, Jemal A. Cancer statistics, 2012. CA Cancer J Clin. 2012;62(1):10-29.

3. Gralow JR, Biermann JS, Farooki A, et al. NCCN task force report: bone health in cancer care. J Natl Compr Canc Netw. 2009;7 Suppl 3:S1-S32; quiz S33-S35.

4. NIH Consensus Development Panel on Osteoporosis. Osteoporosis prevention, diagnosis, and therapy. JAMA. 2001;285(6):785-795.

5. Cornuz J, Feskanich D, Willett WC, Colditz GA. Smoking, smoking cessation, and risk of hip fracture in women. Am J Med. 1999;106(3): 311-314.

6. Feskanich D, Willett W, Colditz G. Walking and leisure-time activity and risk of hip fracture in postmenopausal women. JAMA. 2002;288(18): 2300-2306.

7. Moayyeri A. The association between physical activity and osteoporotic fractures: a review of the evidence and implications for future research. Ann Epidemiol. 2008;18(11):827-835. 
8. Committee to Review Dietary Reference Intakes for Vitamin D and Calcium. Dietary Reference Intakes for Calcium and Vitamin D. Washington, DC: The National Academies Press; 2011.

9. Favus MJ. Bisphosphonates for osteoporosis. N Engl J Med. 2010; 363(21):2027-2035.

10. Black DM, Cummings SR, Karpf DB, et al. Randomised trial of effect of alendronate on risk of fracture in women with existing vertebral fractures. Fracture Intervention Trial Research Group. Lancet. 1996; 348(9041):1535-1541.

11. Harris ST, Watts NB, Genant HK, et al. Effects of risedronate treatment on vertebral and nonvertebral fractures in women with postmenopausal osteoporosis: a randomized controlled trial. Vertebral Efficacy With Risedronate Therapy (VERT) Study Group. JAMA. 1999;282(14): 1344-1352.

12. Black DM, Delmas PD, Eastell R, et al. Once-yearly zoledronic acid for treatment of postmenopausal osteoporosis. N Engl J Med. 2007;356(18): 1809-1822.

13. Rosen LS, Gordon D, Kaminski M, et al. Long-term efficacy and safety of zoledronic acid compared with pamidronate disodium in the treatment of skeletal complications in patients with advanced multiple myeloma or breast carcinoma: a randomized, double-blind, multicenter, comparative trial. Cancer. 2003;98(8):1735-1744.

14. Rosen LS, Gordon D, Tchekmedyian S, et al. Zoledronic acid versus placebo in the treatment of skeletal metastases in patients with lung cancer and other solid tumors: a phase III, double-blind, randomized trial - the Zoledronic Acid Lung Cancer and Other Solid Tumors Study Group. J Clin Oncol. 2003;21(16):3150-3157.

15. Saad F, Gleason DM, Murray R, et al. A randomized, placebo-controlled trial of zoledronic acid in patients with hormone-refractory metastatic prostate carcinoma. J Natl Cancer Inst. 2002;94(19):1458-1468.

16. Boyle WJ, Simonet WS, Lacey DL. Osteoclast differentiation and activation. Nature. 2003;423(6937):337-342.

17. Baron R, Ferrari S, Russell RG. Denosumab and bisphosphonates: different mechanisms of action and effects. Bone. 2011;48(4):677-692.

18. Fizazi K, Lipton A, Mariette X, et al. Randomized phase II trial of denosumab in patients with bone metastases from prostate cancer, breast cancer, or other neoplasms after intravenous bisphosphonates. J Clin Oncol. 2009;27(10):1564-1571.

19. Stopeck AT, Lipton A, Body JJ, et al. Denosumab compared with zoledronic acid for the treatment of bone metastases in patients with advanced breast cancer: a randomized, double-blind study. J Clin Oncol. 2010;28(35):5132-5139.

20. Fizazi K, Carducci M, Smith M, et al. Denosumab versus zoledronic acid for treatment of bone metastases in men with castration-resistant prostate cancer: a randomised, double-blind study. Lancet. 2011;377(9768): 813-822.

21. Henry DH, Costa L, Goldwasser F, et al. Randomized, double-blind study of denosumab versus zoledronic acid in the treatment of bone metastases in patients with advanced cancer (excluding breast and prostate cancer) or multiple myeloma. J Clin Oncol. 2011;29(9):1125-1132.

22. Adler RA, Gill RS. Clinical utility of denosumab for treatment of bone loss in men and women. Clin Interv Aging. 2011;6:119-124.

23. Goodwin PJ, Ennis M, Pritchard KI, Trudeau M, Hood N. Risk of menopause during the first year after breast cancer diagnosis. $J$ Clin Oncol. 1999;17(8):2365-2370.

24. Bines J, Oleske DM, Cobleigh MA. Ovarian function in premenopausal women treated with adjuvant chemotherapy for breast cancer. $J$ Clin Oncol. 1996;14(5):1718-1729.

25. Shapiro CL, Manola J, Leboff M. Ovarian failure after adjuvant chemotherapy is associated with rapid bone loss in women with early-stage breast cancer. J Clin Oncol. 2001;19(14):3306-3311.

26. Burstein HJ, Prestrud AA, Seidenfeld J, et al. American Society of Clinical Oncology clinical practice guideline: update on adjuvant endocrine therapy for women with hormone receptor-positive breast cancer. J Clin Oncol. 2010;28(23):3784-3796.

27. Smith IE, Dowsett M. Aromatase inhibitors in breast cancer. $N$ Engl J Med. 2003;348(24):2431-2442.
28. Amir E, Seruga B, Niraula S, Carlsson L, Ocana A. Toxicity of adjuvant endocrine therapy in postmenopausal breast cancer patients: a systematic review and meta-analysis. J Natl Cancer Inst. 2011;103(17): 1299-1309.

29. Ellis GK, Bone HG, Chlebowski R, et al. Randomized trial of denosumab in patients receiving adjuvant aromatase inhibitors for nonmetastatic breast cancer. J Clin Oncol. 2008;26(30):4875-4882.

30. Brufsky AM, Bosserman LD, Caradonna RR, et al. Zoledronic acid effectively prevents aromatase inhibitor-associated bone loss in postmenopausal women with early breast cancer receiving adjuvant letrozole: Z-FAST study 36-month follow-up results. Clin Breast Cancer. 2009;9(2):77-85.

31. Eidtmann H, de Boer R, Bundred N, et al. Efficacy of zoledronic acid in postmenopausal women with early breast cancer receiving adjuvant letrozole: 36-month results of the ZO-FAST Study. Ann Oncol. 2010; 21(11):2188-2194.

32. Gnant M, Mlineritsch B, Schippinger W, et al. Endocrine therapy plus zoledronic acid in premenopausal breast cancer. $N$ Engl J Med. 2009; 360(7):679-691.

33. Gnant M, Mlineritsch B, Stoeger H, et al. Adjuvant endocrine therapy plus zoledronic acid in premenopausal women with early-stage breast cancer: 62-month follow-up from the ABCSG-12 randomised trial. Lancet Oncol. 2011;12(7):631-641.

34. Coleman RE, Marshall H, Cameron D, et al. Breast-cancer adjuvant therapy with zoledronic acid. $N$ Engl J Med. 2011;365(15): 1396-1405.

35. Schramek D, Leibbrandt A, Sigl V, et al. Osteoclast differentiation factor RANKL controls development of progestin-driven mammary cancer. Nature. 2010;468(7320):98-102.

36. Jones DH, Nakashima T, Sanchez OH, et al. Regulation of cancer cell migration and bone metastasis by RANKL. Nature. 2006;440(7084): 692-696.

37. Mohler J, Bahnson RR, Boston B, et al. NCCN clinical practice guidelines in oncology: prostate cancer. J Natl Compr Canc Netw. 2010;8(2): 162-200.

38. Payne H, Mason M. Androgen deprivation therapy as adjuvant/neoadjuvant to radiotherapy for high-risk localised and locally advanced prostate cancer: recent developments. Br J Cancer. 2011;105(11):1628-1634.

39. Lee RJ, Saylor PJ, Smith MR. Treatment and prevention of bone complications from prostate cancer. Bone. 2011;48(1):88-95.

40. Shahinian VB, Kuo YF, Freeman JL, Goodwin JS. Risk of fracture after androgen deprivation for prostate cancer. $N$ Engl J Med. 2005;352(2): 154-164.

41. Smith MR, Lee WC, Brandman J, Wang Q, Botteman M, Pashos CL. Gonadotropin-releasing hormone agonists and fracture risk: a claimsbased cohort study of men with nonmetastatic prostate cancer. J Clin Oncol. 2005;23(31):7897-7903.

42. Smith MR, Egerdie B, Hernandez Toriz N, et al. Denosumab in men receiving androgen-deprivation therapy for prostate cancer. $N$ Engl J Med. 2009;361(8):745-755.

43. Smith MR, Saad F, Coleman R, et al. Denosumab and bonemetastasis-free survival in men with castration-resistant prostate cancer: results of a phase 3, randomised, placebo-controlled trial. Lancet. 2012; 379(9810):39-46.

44. Task Force. American Association of Oral and Maxillofacial Surgeons position paper on bisphosphonate-related osteonecrosis of the jaws. J Oral Maxillofac Surg. 2007;65(3):369-376.

45. Woo SB, Hellstein JW, Kalmar JR. Systematic review: bisphosphonates and osteonecrosis of the jaws. Ann Intern Med. 2006;144(10): 753-761.

46. Saad F, Brown JE, Van Poznak C, et al. Incidence, risk factors, and outcomes of osteonecrosis of the jaw: integrated analysis from three blinded active-controlled phase III trials in cancer patients with bone metastases. Ann Oncol. 2012;23(5):1341-1347.

47. Cummings SR, San Martin J, McClung MR, et al. Denosumab for prevention of fractures in postmenopausal women with osteoporosis N Engl J Med. 2009;361(8):756-765. 
48. Papapoulos S, Chapurlat R, Libanati C, et al. Five years of denosumab exposure in women with postmenopausal osteoporosis: Results from the first two years of the FREEDOM extension. J Bone Miner Res. 2012; 27(3):649-701.

49. Wong BR, Rho J, Arron J, et al. TRANCE is a novel ligand of the tumor necrosis factor receptor family that activates c-Jun N-terminal kinase in T cells. J Biol Chem. 1997;272(40):25190-25194.

50. Kong YY, Yoshida H, Sarosi I, et al. OPGL is a key regulator of osteoclastogenesis, lymphocyte development and lymph-node organogenesis. Nature. 1999;397(6717):315-323.

51. Anastasilakis AD, Toulis KA, Goulis DG, et al. Efficacy and safety of denosumab in postmenopausal women with osteopenia or osteoporosis: a systematic review and a meta-analysis. Horm Metab Res. 2009;41(10): $721-729$.
52. Watts NB, Roux C, Modlin JF, et al. Infections in postmenopausal women with osteoporosis treated with denosumab or placebo: coincidence or causal association? Osteoporos Int. 2012;23(1):327-337.

53. Pazianas M, Cooper C, Ebetino FH, Russell RG. Long-term treatment with bisphosphonates and their safety in postmenopausal osteoporosis. Ther Clin Risk Manag. 2010;6:325-343.

54. Ibrahim A, Scher N, Williams G, et al. Approval summary for zoledronic acid for treatment of multiple myeloma and cancer bone metastases. Clin Cancer Res. 2003;9(7):2394-2399.

55. Chang JT, Green L, Beitz J. Renal failure with the use of zoledronic acid. N Engl J Med. 2003;349(17):1676-1679; discussion 1676-1679.
Clinical Interventions in Aging

\section{Publish your work in this journal}

Clinical Interventions in Aging is an international, peer-reviewed journal focusing on evidence-based reports on the value or lack thereof of treatments intended to prevent or delay the onset of maladaptive correlates of aging in human beings. This journal is indexed on PubMed Central, MedLine, the American Chemical Society's 'Chemical Abstracts Ser-

\section{Dovepress}

vice' (CAS), Scopus and the Elsevier Bibliographic databases. The manuscript management system is completely online and includes a very quick and fair peer-review system, which is all easy to use. Visit http://www.dovepress.com/testimonials.php to read real quotes from published authors.

Submit your manuscript here: http://www.dovepress.com/clinical-interventions-in-aging-journal 